\title{
14 Vertical integration in a multi-level governance system using the example of the German Resource Efficiency Programme
}

\author{
Maic Verbücheln and Bettina Bahn-Walkowiak
}

\section{Introduction}

Global resource use trends show clear evidence of the challenges that have to be addressed urgently if society is to be prepared for the future. One of the most critical tasks is to preserve natural resources, especially in connection with climate protection. This is, inter alia, reflected in the 17 Sustainable Development Goals (SDGs). For example, target 8.4 requires to 'improve progressively, through 2030, global resource efficiency in consumption and production and endeavour to decouple economic growth from environmental degradation' (United Nations 2019). Furthermore, several other subtasks also indirectly refer to the use of natural resources.

A considerably more efficient if not markedly reduced use of resources and its negative environmental impacts are major challenges of our modern western societies which have to be tackled by policy immediately (Bringezu 2014). Germany is among the few countries that have achieved an absolute decoupling of economic growth of raw material consumption during the period 1995 to 2014. However, the per-capita resource use in Germany in 2014 (measured as raw material consumption) was 15.8 tonnes. Therefore, Germany is still a stable resource-intensive nation with an above-average per capita use compared to Europe (13.4 tonnes) and is also well above the global average, which has been growing to about 12.3 tonnes in 2017 (Eurostat 2019).

Against this background, the German Resource Efficiency Programme (ProgRess) was launched in 2012 and advanced in 2016 and 2020 (BMU 2012; BMUB 2016; BMU 2020). The ultimate goal of ProgRess is to make the extraction and use of natural resources more sustainable and reduce associated environmental pollution as much as possible. By doing this - also with responsibility towards future generations - the programme should create a prerequisite for securing a long-term high quality of life. To bring the policy approaches formulated in ProgRess to reality, efforts to implement resource efficiency measures have to be increased at all levels - from international to regional to local. 
The chapter intends to provide an impetus for the current debate on ProgRess policy development. The chapter identifies, analyses and describes deficits and possibilities of vertical integration of the German programme in particular and derives recommendations for action which may also serve as indications for other strategies. The following sections are based on results of the advisory report 'Vertical integration of the national resource efficiency programme ProgRess (VertRess)' (Verbücheln \& Bahn-Walkowiak unpublished), conducted by the German Institute of Urban Affairs (Difu) and the Wuppertal Institute for Climate, Environment and Energy on behalf of the German Environmental Agency (UBA) and the Federal Ministry of the Environment, Nature Conservation and Nuclear Safety (BMU).

\section{The German federal system and the present structure of ProgRess}

Within the debate on policy coherence and policy integration, a distinction is usually made between horizontal and vertical integration (Howlett, Vince \& del Rio 2017; Bahn-Walkowiak \& Wilts 2017; Candel \& Biesbroek 2016; Jordan \& Lenschow 2010). Horizontal integration strives for better networking and connection between the various policy areas such as the economy, finance, social affairs, or in environmental policy areas such as climate protection, mobility, energy. Vertical integration seeks better coordination and cooperation between the levels of action and actors in a specific topical field. Both aspects are eminently important, but this chapter will focus on the vertical dimension, which is often neglected. Based on the theoretical policy integration approach, a thorough analysis of the relevant documents, the legal responsibilities and subsequent influences of the governance levels is conducted and the architecture of the governance elements of the programme studied to identify deficits and potentials in the current structure.

Germany is considered to be a pioneer in developing a national resource efficiency agenda (EEA 2016; EEA 2020). With the publication of the 'Programme for the sustainable use and conservation of natural resources' (ProgRess I) in 2012, the German Federal Government has set a milestone for the development of a dedicated policy mix in this field. ProgRess was updated in 2016 (ProgRess II) and recently in 2020 (ProgRess III). The implementation process is challenging, and aspirations differ from reality, thus calling for new action and approaches.

\section{Construction of the federal system in Germany}

The German Federal system is complex. In addition to the Federation, the German Federal Republic consists of 16 partly sovereign Federal States (Länder), which - according to the German constitution - have to fulfil their state tasks. The concurrent legislation assigns different legislative tasks to the federal government and the federal states. 
In practice, various areas with a high resource relevance are regulated at Länder level (e.g. the innovation policy, public support programmes, public procurement, sustainability agreements with individual companies or voluntary commitments in specific sectors or industries, construction and regional planning and the expansion and optimisation of waste management and recycling (infra-)structures as well as waste prevention and re-use strategies and measures). At the same time, important resource-relevant policy areas in which the federal states have outstanding competencies are not (yet) part of ProgRess or are addressed in other strategies (e.g. mobility/traffic, land management, water balance).

Following the federalism reform in 2006, nature and landscape conservation, soil distribution, spatial planning, and water management are jointly regulated areas by government and federal states, which, of course, also have great municipal relevance (see below). Accordingly, the resource efficiency programme assigns tasks to the respective levels and the 2016 update reports on the specific level activities.

\section{Structure of the German Resource Efficiency Programme (ProgRess)}

ProgRess II consists of ten action areas with over 120 individual policy approaches. Unlike the broad European concept of resources (Eurostat n.d.), ProgRess focuses on the material use of resources, including the related environmental impacts. The programme addresses a large number of different activity levels (as shown in Figure 14.1) but bases mainly on voluntary activities and instruments.

\section{ProgRess implementation mechanisms}

The governance of ProgRess is shared by the Federal Environment Ministry and Federal Environment Agency (here: BMU and UBA). Main elements in the implementation process of ProgRess are:

- A National Platform for Resource Efficiency (NaRess), established in 2013. Initially comprising the Federal Government and industry associations, the membership was extended to further groups such as environmental organisations, unions and local authority associations. NaRess serves as a platform for sharing information on members' resource efficiency activities and supports the implementation and onward development of ProgRess (BMUB 2016).

- The Centre for Resource Efficiency (VDI ZRE), established in 2011. It develops products notably comprising sector-specific support, methodologies, and information. They include, for example, resource efficiency checks and process systematisation tools to assist manufacturing enterprises with internal resource efficiency improvement projects (BMUB 2016). 


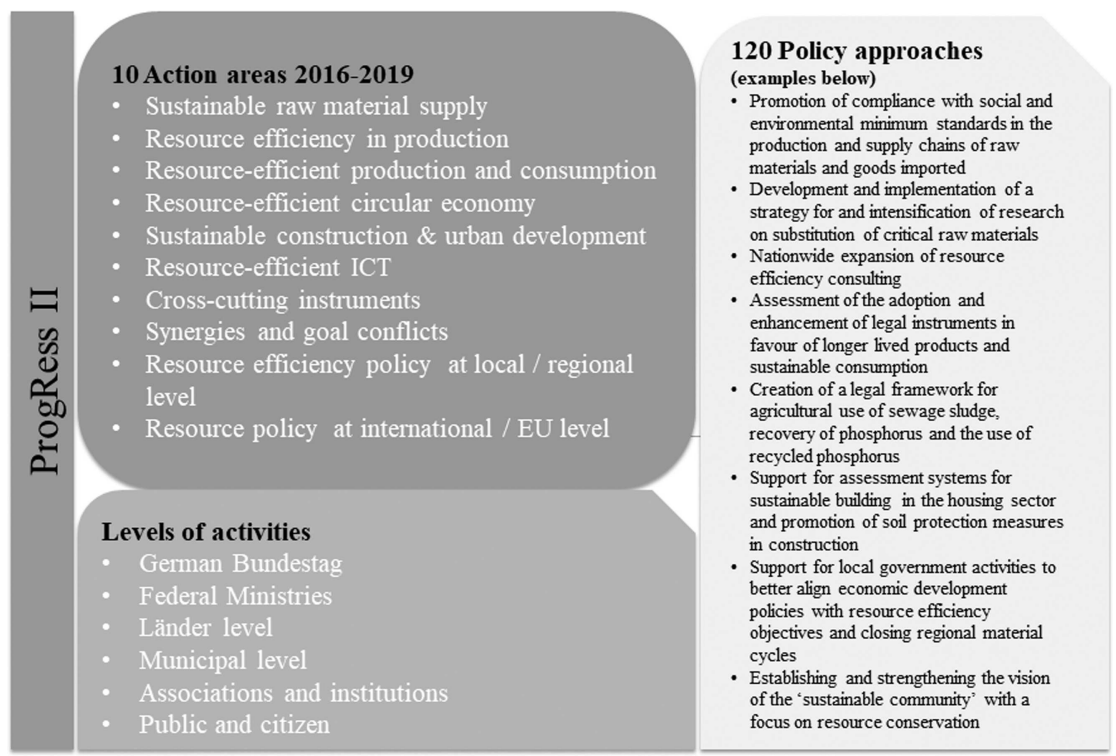

Figure 14.1 Elements of the German Resource Efficiency Programme (ProgRess 2016-2020).

Source: own illustration; modified from Bahn-Walkowiak et al. (2019: 44).

- The Resource Efficiency Network (NeRess), established in 2007. The network combines inter-disciplinary expertise and experience in resource efficient production, products, and management (BMUB 2016).

The implementation of ProgRess has been transparently communicated from a range of different thematic perspectives in biannual public Resource Efficiency Network (NeRess) meetings, biannual meetings of the Länder, and conferences of the European Resources Forum (ERF) and the National Resources Forum (NRF).

\section{ProgRess evaluation}

A recent evaluation assessed ProgRess to be a successful strategy with important network components and an elaborated updating process. However, the impact on resource use clearly needs to be improved, and material flows need to be optimised (Bahn-Walkowiak et al. 2019; Verbücheln \& WagnerEndres 2018). The leading research question is why ProgRess does not have a greater penetration on all levels and how can this be improved. The objective of this chapter is therefore to highlight options for better integration of Länder and municipalities in the further development and implementation of ProgRess. 


\section{Länder: responsibilities and influence on action areas of ProgRess}

To date, all 16 Länder have a sustainability strategy, but only 3 of them have a specific strategy for resource efficiency (i.e. Baden-Wuerttemberg, Hessen, Saxony). The Länder that have integrated relevant resource policy activities into their environmental policy are Bavaria (Bavarian Raw Materials Strategy), Saarland (Saar Environmental Pact) and North-Rhine-Westphalia (Sustainability Strategy).

Federal states have various legal and other possibilities to, directly and indirectly, influence the consumption of raw materials. To mention is the field of land management, construction policy, waste and circular flow policies, public procurement, mining laws, regulation of environmental impact assessments. However, some of the resource relevant intervention points of the Länder are not within the defined scope of action of ProgRess, but go beyond it.

The scope for action of the Länder in the areas of raw material extraction and supply, production, consumption, circular economy and sustainable urban development (which represent five of ProgRess' total ten areas of action) is consequently vast and diverse. The authors identified several hundred intervention points in the form of different economic, legal, informational, or sectoral instruments. Multiplied with the individual countries an impressive number of options occurs.

ProgRess areas, which are in the exclusive responsibility of the Länder, are not found in the 120 policy approaches. On the other hand, about 60 of the policy approaches are at least partly under the responsibility of the Länder. That means that competencies/responsibilities are to be shared with the other governance levels and coordination is required. Multi-actor responsibilities are always at risk to lead to no actor feeling responsible, sometimes resulting in inaction.

\section{Municipalities: responsibilities and influence on action areas of ProgRess}

Besides the sovereignty of the Länder, it is important to mention that the local self-government of German municipalities includes the right to implement most of the public responsibility independently. However, the municipalities implement obligatory as well as optional tasks on the local level in general. Concerning the constitutional law, it is not possible to allocate duties directly to the municipalities by the Federal State - only the Länder have this option by using their legislation. Therefore, the Federal Government has to go via the Länder level or use other means such as programmes or incentives to address municipalities.

On the municipal level, large quantities of resources are required, such as building materials, water and energy. Resource efficiency is a cross-sectional local and regional issue. Hence, the local politicians, administration and 


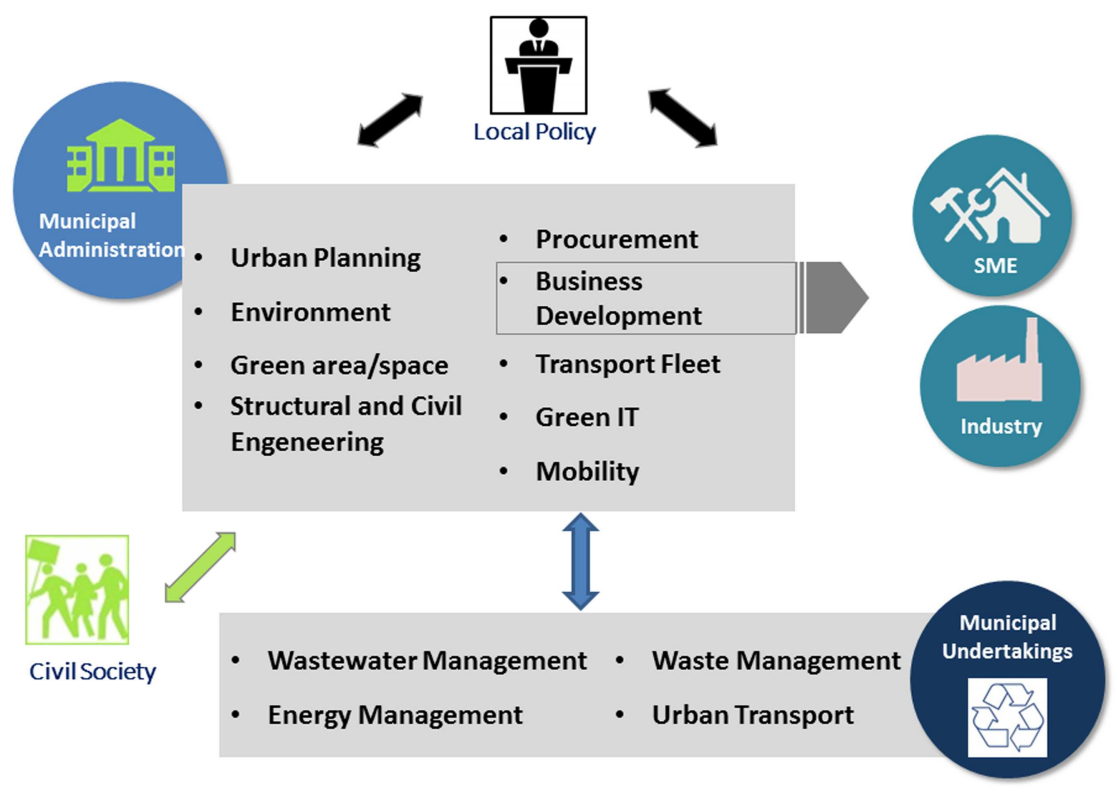

Figure 14.2 Actors and action areas in resource efficiency on the local level.

Source: own illustration; modified from Verbücheln and Wagner-Endres (2018).

municipal undertakings play an important role in resource efficiency, along with actors of civil society and private enterprises (Verbücheln \& Wagner-Endres 2018). Figure 14.2 shows the actors and municipal actions fields which have a direct or indirect effect on the use of natural resources.

The local politics (e.g. mayor, council, a county office) sets the agenda on the local level, produces statutes and has a monitoring and controlling function, for example, vis-à-vis the local administration (CEMR 2013). The municipal administration has competencies in different resource relevant action areas (e.g. urban planning, environment; see Figure 14.2). The daily work of the administration comprises planning and implementation. The municipal business development units support small and medium enterprises (SME) or industries in business parks (e.g. resource efficiency). Municipal infrastructure undertakings and economic enterprises (private law organised) take duties from the local government. They mostly provide local and regional infrastructures like energy and water supply, public transport, or waste management. The mentioned actors are in Germany part of the so-called 'municipal family'. The civil society (e.g. Transition Town) pushes bottom-up processes and is important for local action.

Figure 14.2 shows how important the role of municipalities is for the implementation of resource relevant activities. In addition, municipalities play further different roles on the local and regional level - they are initiators, 
networkers, or partners for the implementation of any resource relevant activities. Local actors have the knowledge to identify on-site potentials, develop networks and adopt measures.

However, there are different interfaces between the 120 individual policy approaches which are described in ProgRess II and the action areas of the municipalities. The evaluation has shown that 34 of the policy approaches are optional, and three are obligatory for the municipalities (Verbücheln and Bahn-Walkowiak, unpublished). For example, the following ProgRess policy approaches have a direct link to municipalities: 'Environment-friendly expansion of material use of regenerative resources' or 'resource-efficient neighbourhood and building development, construction, refurbishment, and use' or 'resource-efficient infrastructure' (BMUB, 2016). An effective implementation of such policy approaches is not possible without the municipalities. Furthermore, municipal activities affect resource relevant action fields which are not included in ProgRess, for example, the field of mobility.

There is a multitude of municipal activities which have a direct and indirect effect on natural resources. But on the local and regional level, resources are not a single action field. In the municipalities, there are usually no separate departments, authorities, or single persons who are responsible for resource protection or resource efficiency. Approaches are mostly sectoral. Furthermore, questions concerning resource efficiency play a minor role in most of the municipal action areas (e.g. urban planning). There are still potentials on the local and regional level which have to be realised in an efficient and consistent way.

\section{Deficits and potentials of the vertical structure of ProgRess}

Institutional transmission belts of multi-level systems have to mesh to ensure percipience, responsibility, and also legitimisation. It is important to support activities for the implementation of resource efficiency measures on Länder and municipal level. However, the description above sheds a first light on the weakness of ProgRess: the decentralised design of the resource policy with rather guiding than obliging instruments entails a patchwork of effective and ineffective interventions and (all too often) non-interventions. Without an at least mandatory and specific resource policy addressing the most resource-intensive sectors, the tiger may remain toothless.

The following sections will highlight some deficits concerning the vertical structure of ProgRess as well as the content in more detail.

\section{Policy development process}

Firstly, we have to point out the vertical structure for the development of ProgRess (see Figure 14.1). This structure is based on an inter-ministerial exchange between the Federal Ministry for the Environment and the 
Federal Ministry for Economic Affairs and Energy, which is, among others, supported by the 'National Platform Resource Efficiency' (NaRess). In NaRess, stakeholders from business and economy as well as the federal states are, for instance, directly addressed by the format. It is a structural deficit that stakeholders from the municipalities are addressed less. This means one of the major actors is only slightly considered in the follow-up development process of ProgRess III. The Länder are involved in the vertical process. It needs to be mentioned, however, that better horizontal exchange and cooperation between the Länder in the context of resource policy would also be reasonable.

In contrast to the ProgRess approach, the German Waste Prevention Programme is a joint programme of the Federal Government and the Länder to which both governance levels are committed. It is thus an example of vertical integration. The Länder either adopt the guidelines or have to develop independent waste prevention programmes. In addition, dialogue takes place for the development of the programme/strategy to involve stakeholders such as representatives of public institutions, industry players, NGOs, scientists, etc. For ProgRess, however, there are considerably more process elements established for the coordination of the actors (NaRess, NeRess, etc.), but there is no reciprocal commitment for participation.

Furthermore, the integration of waste and resource policy is challenging from horizontal and vertical perspective due to the largely separate responsibilities, activities and actors, which can be found in almost all competent authorities from the national to the municipal level.

\section{Content and representation}

Secondly, there are deficits in the content of ProgRess. It is important to take into account the partial overlapping, but not congruent actors and institutions targeted by ProgRess - for example, in the context of resource efficiency and circular economy.

The integration of spatial planning, land management, and resource conservation is insufficiently addressed by ProgRess. The Länder-specific possibilities for action in this context are, therefore, insufficiently guided by aspects of resource protection. Sustainable urban development does not cover urban sprawl or the continuing increase in traffic areas and parking spaces.

This has partly led to the countries concentrating on micro-economic resource efficiency and non-regulative instruments to nudge activities, albeit very successfully. More than 70 activities were newly created since the update of ProgRess II in 2016 and identified in the study. 15 Länder offer public financial programmes in order to support enterprises in their efforts to strive for more resource efficiency. However, it has become increasingly clear that the focus on industrial win-win solutions is only successful to a limited extent and the resistance is high, not only in Germany (Tukker \& Ekins 2019). 
Also, critical sectoral fields of action like the mobility are furthermore not part of ProgRess. The areas construction, housing, and mobility however traditionally play a major role in both state and local policy, especially from an economic point of view. ProgRess' tension between a very broad and comprehensive design of 120 approaches in ten action areas and a narrow focus on abiotic raw materials leads to partly unclear responsibilities and possibly to the problem that actors not feel authorised at all. Moreover, some examples show that the used headings for the action areas in ProgRess are partly vast and not concrete, whereas the subheadings are very concrete. The wording has to be optimised with a focus on the target groups - including a direct designation.

\section{ProgRess implementation}

Thirdly, we have to look at the implementation processes. ProgRess is a policy mix acting in a multi-level system, but because of the large number of stakeholders and high amount of levels and legal spheres that are touched, the implementation of the programme is highly complex and confronted with several barriers. This is, inter alia, complicated by changing actors (political configurations) and long-term institutional arrangements.

At Länder level, responsibilities for energy and resource efficiency are usually not split (no state has a resource efficiency ministry). The targeted use of synergies, however, is an exception, for example, for building renovation. As a consequence, the main activities of the Länder to foster resource efficiency have a focus on the industry and small and medium-sized enterprises. An example is the promotion of the information platform Centre for Resource Efficiency (VDI ZRE) which is closely connected to the Association of German Engineers (VDI).

ProgRess is almost unknown on the municipal level, and integrated incentives to engage in resource efficiency do not exist. Moreover, there is no direct contact person on the local level concerning the issue of resource efficiency, despite several intersections. This is a main deficit because the implementation of resource efficiency measures is often driven and implemented on the local level by actors from the municipalities. Better information, as well as incentives for the municipalities, are missing so far.

To foster the protection of natural resources, all potentials in all fields of actions in the different governance levels have to be addressed in the right way. Not all possibilities and potentials, however, have been exhausted on a local and regional level, which is why the issue of resource efficiency needs has to be expanded with the spotlight on actors such as municipalities and their activities. Local management systems aiming for cross-sectoral optimisation of material flows are not firmly entrenched, particularly in cities. On this background, the objective is to optimise the vertical integration of the Länder as well as the municipalities within the further development and implementation of ProgRess. 


\section{Recommendations for better vertical integration of the resource efficiency policy in Germany}

\section{Better structural integration of the Länder and municipalities}

In the past, ProgRess has focused on the optimisation of resource efficiency in small and medium-sized enterprises on two levels. First, through the involvement of association representatives during the development of ProgRess and second, concerning the implementation of measures (e.g. information and incentives for the enterprises). The attention should also, overall, be expanded to other target groups which are relevant for resource efficiency, in particular, the federal states and the municipalities. The involvement of federal states and municipal organisations should be optimised because they are not yet fully integrated in the information and participation formats of ProgRess. A better dialogue between Federal State, Länder and municipalities has also to be put on the agenda.

Therefore, an adaptation or optimisation of the structure of the National Platform Resource Efficiency (NaRess) as part of the ProgRess vertical structure is recommended. A modified structure of the NaRess organisation for a better exchange of information and participation between Federal Ministries, Länder, and municipalities are reasonable. Following levels are recommended:

a Optimisation of the cooperation between Federal Ministries, also with a view on legislation framework, for example by the establishment of an inter-ministerial committee (including the Ministry of Transport and the Ministry of Food and Agriculture).

b Optimised integration and exchange with a view on Länder and municipalities (including associations like the Association of German Cities, German Association of Towns and Municipalities, German County Council or German Association of Local Utilities).

c Use and development of new working groups and cross-sector roundtables with municipal representatives - also with representatives from the administration of bigger cities for examples. For this purpose, existing groups can be used or extended.

All three levels mentioned above have to be connected for an exchange. However, not only the structure but also the format and the content of the NaRess meetings have to be amended.

The governance levels and groups of interests have to be better integrated into the follow-up process to ProgRess III (so far, the focus is on enterprises).

\section{Advancement of the content of ProgRess III}

Resource efficiency is a cross-sectional task, and better integration of the different sectors/policy fields should be designed to enable synergies. 
Moreover, a stronger focus on activities like urban planning, building and construction, and mobility - all inducing highly resource-intensive material streams and land use - is required. It thus also touches on horizontal integration issues, because integrated approaches are needed.

\section{Increase the awareness level of ProgRess}

The awareness level in the municipalities to resource management issues has to be improved clearly. Therefore, the strategic approaches which are already formulated in ProgRess II have to be filled with life. Those approaches are:

1 consolidation of the concept 'sustainable municipalities' - focus: resource efficiency;

2 establishment of specific information - and consultation offers for municipalities; and

3 support of municipal activities which foster the regional economic development regarding resource efficiency.

Against this background, the development of an information platform similar to the VDI ZRE - for municipalities as a target group is an effective way for the optimisation of the awareness on the local level. The information has to address the local level in general which includes the local policy, the administration, the local business development as well as the civil society. For the implementation of integrated approaches, all these stakeholders play an important role.

\section{Incentives for relevant local stakeholders}

The programme is largely based on voluntary activities and instruments. This, however, also touches on the outreach to the target groups: regulatory and economic instruments are naturally perceived much more strongly by all sections of the society.

Incentives are also of integral importance for the cross-sectional topic of resource efficiency to be promoted on the municipal level. A subsidy programme and/or competition and/or the financing of staff (e.g. resource efficiency manager) should be taken into account. This is important also for the awareness rising among actors on the local level but not at least for consumers who are all directly affected by local decision-making in the context of waste, mobility and floor-space management if they are done under resource-efficient aspects.

\section{General conclusions and outlook}

A shift in resource use patterns is inevitable when we want to take the climate crisis seriously. Although this chapter has focused primarily on institutional 
vertical integration in a particular programme in a single country, it is clear that resource conservation is an essential part of any other resource-dependent environmental policy field such as climate protection and land use. With a view on resource scarcity, however, it is also an issue of economy and peace. Resource relevant activities must be brought closer in a more systematic way at national, European and global levels. The segmentation of federal environmental policy in Germany has so far continued at the state level. Better horizontal cooperation between the states should be an objective too!

With a view to European policy development, it has become apparent in recent years that resource efficiency is increasingly understood as an essential element of a broader circular economy. This means highly complex challenges and research demand, not only in the context of global value chains for resources and waste but also and especially in the regional-municipal area, which is characterised by path-dependent infrastructures and small-scale regulation of waste management at a day-to-day basis. A huge number of extremely different actors and stakeholders has to be brought to the table to discuss common objectives and target conflicts in the first place. This points to a necessary indepth analysis target and conflict-of-goals.

With a specific view on policy integration and especially vertical policy integration, the question should be investigated in more detail as to how such a complex implementation process can be made more participatory and inclusive without the most powerful industries becoming the main decisionmakers in the long run. As the Federal Ministry states: 'Comprehensive public participation is vital for gaining broad acceptance of the programme' (BMU 2019) and has introduced a citizens' dialogue for ProgRess III for the second time (comprising a total of 250 randomly selected members of the public who will bring in their suggestions for improving the programme). This extraordinarily successful process could, for example, also be a viable way for local decision-makers in the municipalities to become better involved.

A concluding remark shall acknowledge that new programme 2020-2023 has taken up some of the aspects suggested in this chapter. For example, the promotion of local public transport and an alignment of the municipal economic development towards resource efficiency and closing regional material cycles have been newly included as two priorities.

\section{References}

Bahn-Walkowiak, B. and Wilts, H. (2017). The Institutional Dimension of Resource Efficiency in a Multi-level Governance System - Implications for Policy Mix Design. Energy Research \& Social Science, Special issue: Policy mixes for energy transitions, edited by K. S. Rogge, F. Kern, M. Howlett. Vol 33, November 2017, 163-172. doi: 10.1016/ j.erss.2017.09.021.

Bahn-Walkowiak, B., Koop, C., Meinel, U., Nicolas, J. and Wilts, H. (2019). Evaluation des deutschen Ressourceneffizienzprogramms ProgRess: Teilbericht. TEXTE No. 43/2019. Dessau-Roßlau: Umweltbundesamt. 
BMU (2012). German Resource Efficiency Programme (ProgRess) - Programme for the Sustainable Use and Conservation of Natural Resources. Decision of the Federal Cabinet of 29 February 2012. Berlin: Federal Ministry for the Environment, Nature Conservation and Nuclear Safety (BMU). Retrieved from www.neress.de/fileadmin/media/files/ Progress/120309_Overview_ProgRess_engl_01.pdf (14 May 2019).

BMU (2019). German Resource Efficiency Programme (ProgRess) - an Overview. Retrieved from: www.bmu.de/en/topics/economy-products-resources-tourism/resource-efficiency/ overview-of-german-resource-efficiency-programme-progress (30 August 2019).

BMU (2020). Deutsches Ressourceneffizienzprogramm III 2020-2023 Programm zur nachhaltigen Nutzung und zum Schutz der natürlichen Ressourcen. Berlin: Federal Ministry for the Environment, Nature Conservation and Nuclear Safety (BMU). Retrieved from www.bmu.de/download/deutsches-ressourceneffizienzprogramm-progress-iii (3 August 2020).

BMUB (2016). German Resource Efficiency Programme II - Programme for the Sustainable Use and Conservation of Natural Resources. Berlin: Federal Ministry for the Environment, Nature Conservation, Building and Nuclear Safety (BMUB).

Bringezu, S. (2014). Targets for Global Resource Consumption. In: M. Angrick, A. Burger, and H. Lehmann (Eds.). Factor X. Eco-Efficiency in Industry and Science. Vol 29. (pp. 41-64). Dordrecht: Springer.

Candel, J. J. L. and Biesbroek, R. (2016). Toward a Processual Understanding of Policy Integration. In: Policy Sciences, 49(3), 211-231. https://doi.org/10.1007/s11077-0169248-y.

CEMR (2013). Local and Regional Government in Europe - Structures and Competencies. Brussels: Council of European Municipalities and Regions (CEMR).

EEA (2016). More from Less - Material Resource Efficiency in Europe: 2015 Overview of Policies, Instruments and Targets in 32 Countries. EEA Report No 10/2016. Prepared by Paweł Kaźmierczyk et al. Copenhagen: European Environment Agency.

EEA (2020). Resource Efficiency and the Circular Economy in Europe 2019: Even More from Less; an Overview of the Policies, Approaches and Targets of 32 European Countries [authors: Kazmierczyk, P., Geerken, T. Contributors: Montalvo, D., Daniell, J., Manfredi, S., Ullstein, B., Bahn-Walkowiak, B. ...]. EEA-Report No. 26/2019. Copenhagen: European Environment Agency, 2019. Retrieved from www.eea.europa.eu/ publications/even-more-from-less (3 August 2020).

Eurostat (n.d.). Environmental Data Centre on Natural Resources - Overview - Natural Resource Concepts. Retrieved from https://ec.europa.eu/eurostat/web/environmentaldata-centre-on-natural-resources/overview/natural-resource-concepts (28 August 2019).

Eurostat (2019). Material Flow Accounts and Resource Productivity. Retrieved from https://ec.europa.eu/eurostat/statistics-explained/index.php/Material_flow_accounts_ and_resource_productivity\#Raw_material_equivalents_.E2.80.94_towards_a_global_ perspective (30 August 2019).

Howlett, M., Vince, J. and del Rio, P. (2017). Policy Integration and Multi-Level Governance: Dealing with Vertical Dimension of Policy Mix Designs. In: Politics and Governance, 5(2), 69-78. https://doi.org/10.17645/pag.v5i2.928.

Jordan, A. and Lenschow, A. (2010). Environmental Policy Integration: a State of the Art Review. In: Env. Pol. Gov. 20, 147-158 (2010). DOI: 10.1002/eet.539.

Tukker, A. and Ekins, P. (2019). Concepts Fostering Resource Efficiency: A Trade-off Between Ambitions and Viability. In: Ecological Economics 155(2019), 36-45. https://doi. org/10.1016/j.ecolecon.2017.08.020. 
United Nations (2019). SDG Indicators - Metadata repository. Retrieved from https:// unstats.un.org $/ \mathrm{sdgs} /$ metadata/ ?Text $=\&$ Goal $=8 \&$ Target $=8.4$ (29 August 2019).

Verbücheln, M. and Bahn-Walkowiak, B. (unpublished). Implementierung und Fortschreibung des Deutschen Ressourceneffizienzprogramms auf der Ebene der Bundesländer und Kommunen - Endbericht (VertRess). Im Auftrag des Umweltbundesamtes.

Verbücheln, M. and Wagner-Endres, S. (2018). Hemmnisse und Potenziale zur Ressourceneffizienzsteigerung durch Optimierung regionaler und lokaler Stoffkreisläufe und Stoffströme - RegioRess - Abschlussbericht. TEXTE No. 63/2019. Dessau-Roßlau: Umweltbundesamt. 